\title{
Improving communication and support for men with prostate cancer
}

\author{
Chris Hiley
}

It's not conventional to admit that you are stating the obvious, but sometimes a statement of the obvious has to be made. All patients with prostate cancer are men. Although this is obvious, it might shift some perspectives into an interesting pattern. How is prostate cancer communicated between men and their doctors? How does information travel? Men value information, but we need to know more about how to support men with prostate cancer and meet their information requirements - their access to information clearly needs to be improved. Deficiencies in support and communication explain some of the levels of dissatisfaction with care expressed by men with prostate cancer in the UK at present.

On 25 February 2005, the National Audit Office in the UK published a report by the Department of Health (Tackling cancer: improving the patient journey: report by the Controller and Auditor General [http://www. nao.org.uk/publications/nao_reports/04-05/ 0405288.pdf]), which investigated patient experience of lung, breast, bowel and prostate cancer services. Responses were received from 4,300 people, including 609 men with prostate cancer who gave the least positive responses to 54 out of 80 questions and gave the most positive responses to only 8 questions. As many as $11 \%$ of men reckoned they had never discussed the side effects of treatment, and $20 \%$ wanted more information on how treatment had gone. In The Prostate Cancer Charity survey of 1,200 men the outcome was even worse; $24 \%$ of men felt the hospital specialist or nurse had not given them enough information about the treatment choices available. Moreover, $19 \%$ of men felt they hadn't received a full explanation of any side effects they might experience, and $20 \%$ were not satisfied with the information they received.

More information, delivered more effectively is a considerable part of the answer to the problem. But there's space for some further analysis. Professor Clive Seale from the UK's Brunel

\section{Men value \\ information, \\ but we need \\ to know more \\ about how to \\ support men \\ with prostate \\ cancer and \\ meet their \\ information \\ requirements.}

C Hiley is Head of

Policy and Research

at The Prostate Cancer Charity, London, UK.

Competing interests

The author declared she has

no competing interests.

www.nature.com/clinicalpractice doi:10.1038/ncponc0554
University has led a study that assessed the ways in which men with prostate cancer and women with breast cancer use the internet to cope with their illness (Seale C et al. [2006] Soc Sci Med 62: 2577-2590). Men were more likely than women to use the internet to access factual information and details on the best medical treatments. By contrast, women used the internet to seek emotional support and to discuss the impact the cancer had on their relationships.

Does the historical and social emphasis on women and breast cancer mean that current models of information and support are rather too 'female' than is meaningful for men with prostate cancer? I suggest that support for men has to be delivered in a specific and tailored fashion, and lessons from the experiences of women with breast cancer may not easily be transposed. Generalizing outrageously, if women with breast cancer seek support that secures their place in the community, and men seek support that reinforces their place as individuals, using the wrong model for support and information could mean that men are not well cared for.

You might think that men should be better suited than women to getting cancer-the language is all theirs, being male, military and action oriented; battling prostate cancer; the fight against prostate cancer; the search for new weapons against prostate cancer; 'soldiering on'; 'on the offensive'. But as the stereotype indicates, 'communication' is not a male thing. I wonder what happens in prostate cancer consultations where the doctor and 'patient' are both men and what consequences there may be for satisfaction with care and psychological wellbeing. Men who won't ask, talking to men who won't say; perhaps doctors should encourage men to ask more about their cancer and seek emotional support.

Should information and communication of prostate cancer be gender sensitive, and do we need to understand a lot more about men and their lives with prostate cancer? Yes, it does, and yes, we do. 